\title{
Evolution of the commercial blocks in ancient Beijing city from the street network perspective
}

\author{
WANG Fang ${ }^{1,2}$, HE Jing ${ }^{1}$, JIANG Chunyan ${ }^{1}$, LI Yixi ${ }^{3}$ \\ 1. Sino-German Joint Laboratory on Urbanization and Locality Research (UAL), College of Architecture and \\ Landscape Architecture, Peking University, Beijing 100871, China; \\ 2. Key Laboratory for Earth Surface Processes, Ministry of Education, Peking University, Beijing 100871, China; \\ 3. College of Urban and Environmental Sciences, Peking University, Beijing 100871, China
}

\begin{abstract}
The synergistic relationship between urban functions and street networks has always been a focus in the field of urban research and practice. From the perspective of street networks, by adopting space syntax, this study analyzed the deep structural characteristics and potential evolution rules of commercial blocks attached to street networks in different periods, as well as the corresponding economic, political, and cultural characteristics of ancient Beijing city over the past 800 years. By combining these with changes in the street network, we further explained the function mechanism of layout and level adjustment in commercial blocks, and the influence of the street network on commercial blocks in the process of historical change. The main conclusions included the following: (1) The urban centripetal-centrifugal siphon effect: the layout form, topological structure, and traffic mode changes in the street network had corresponding guidance for the layout and hierarchical system of commercial blocks, while the centripetal development of the street network could guide the agglomeration effect of commercial blocks, although centrifugal development caused commercial blocks to display outward evacuation. (2) Stage transformation from mutation node to smooth development: the layout of commercial blocks came to depend on the ability to cross the commuting flow center, which originally relied on the accessibility of transportation nodes as local centers. Changes in traffic modes mainly affected the adjustment of the first-level commercial blocks, which easily led to overall layout mutation. Traffic levels have an obvious positive hierarchical relation with the second- and third-level commercial blocks. (3) The adaptation of traditional commercial blocks to the needs of a modern city: affected by the different emerging times and unevenness of the original commercial foundation, commercial blocks have formed various developmental models that meet the needs of modernization, and reach a balance between cultural continuity and functional adaptation.
\end{abstract}

Keywords: commercial block; street network; urban spatial-temporal evolution; space syntax; ancient Beijing city

Received: 2017-11-27 Accepted: 2018-01-30

Foundation: National Natural Science Foundation of China, No.51778005; Sino-German Center (National Natural Science Foundation of China and German Science Foundation), No.GZ1201

Author: Wang Fang, $\mathrm{PhD}$ and Professor, specialized in planning theory and method of locality in built environment. E-mail: wfphd@pku.edu.cn 


\section{Introduction}

The study of the synergistic relationship between urban function and street network has always been a matter of hot debate. Relying on the street network, commercial blocks, as the spaces in which urban life and publicity coexist, are symbols of the city's economic level and prosperity. The maximization of economic and social benefits can be realized when commercial blocks are integrated into the overall structure of the city and are conjoined with street network centers. The evolution of the spatial distribution and hierarchical structure of commercial blocks can reflect social changes and lifestyle transformations, and is also helpful in rethinking the interaction relationship and function rules between the city's culture and spatial structure during its historical development.

Beijing is the political and cultural center of China. Its ancient city is not only a historical and cultural area that remains and continues traditional contexts, but also a central area of Beijing's geographical space and social economy. Its commercial development has gone through several important historical periods, including the Yuan (1271-1368), Ming (1368-1644) and Qing (1644-1911) dynasties, the Republic of China (1912-1949), and the People's Republic of China (1949-). At last it formed a typical commercial layout and distinct hierarchical characteristics. Under the drastic influence of various factors, the interaction between the politics of the "city" and the economy of "municipality" is remarkable. The commercial blocks of ancient Beijing city, which rely on the development of the street network, have constantly adapted and adjusted in the course of its long-term dynamic evolution. Ancient Beijing city has experienced many dynastic changes and different regimes, from feudal monarchy to open democracy. The structure of commercial blocks has gradually been converted to a wide open and diversified commercial system that no longer reflects its strong feudal political background. The change could be seen in the books entitled as Records of Cities and Walls (Mandarin: chen yuan shi lue, which was compiled in the Qing Dynasty and recorded the history of Beijing and its historical sites), Records of Alleys in Beijing (Mandarin: jing shi fang xiang zhi gao, which was compiled in the Qing Dynasty and was a geography of alleys, temples, houses and halls in Beijing), and Research of Beijing (Mandarin: yan du cong kao, which was compiled in 1929 during the Republic of China and was composed of three parts, including contents, appendix and notes). The renewal of the ancient Beijing city coexisted with the expansion of the new city. The street network mode of "checkerboard + radioactive ray + loop" has led to the circular expansion of the new city on the basis of the ancient city center. This then drove the commercial blocks of the ancient city to experience centripetal agglomeration or centrifugal evacuation (Gao, 1989; Yang, 1994; Sheng et al., 2013). Beijing commercial blocks have accumulated profound historical deposits. However, with the transformation of modern lifestyles and consumption habits, traditional commercial blocks have undergone modernization (Wu et al., 2001). In the development of the commercial blocks of ancient Beijing city, the competition between top-down government planning and bottom-up self-organization construction was obvious, resulting in gradual or drastic changes in the structure of commercial blocks (Qi, 2011; Qi et al., 2014; Wu et al., 2016).

\subsection{Evolution of Beijing commercial centers}

Beijing has a more than 3000-year history of city construction and a more than 800 -year 
history of capital construction. During the change of dynasties, Beijing formed local and typical commercial blocks. The original commercial block emerged when the city was the capital of the Yan Kingdom during the Zhou Dynasty (1046-256 BC), and experienced fluctuations from the pre-Qin Dynasty (211-21 BC) to the Sui (581-618) and Tang (618-907) dynasties, and at last large-scale commercial blocks were formed when the city was the Southern Capital of the Liao Dynasty (916-1125) and then the Mid-capital of the Jin Kingdom (1115-1234). The interaction between Beijing's "city and market" mainly began during the period of the Great Capital of the Yuan Dynasty and its construction conformed to the planning principle of Rites of the Zhou Dynasty (Mandarin: zhou li, an ancient ritual text, was supposedly written by the Duke of Zhou in the Western Zhou Dynasty (the 11th century-771 BC)): The Records of Examination of Craftsman (Mandarin: kao gong ji, which was compiled in the Spring and Autumn Period (770-476 BC). There were originally six parts in Rites of the Zhou Dynasty; however, the sixth part was lost, and later kao gong ji was added as a replacement), "the palaces are located in the front, while the markets are located in the back", which contributed to the prosperity of the city's commercial blocks. In the Ming Dynasty, the commercial blocks expanded further. The commercial center shifted to the outer city of the south, and gradually formed flourishing markets and temple fairs. "Among outer cities, the south is the most prosperous. In the city, the east part is less prosperous than the south, and the west part is less prosperous than the east, and the north part is less prosperous than the west" (Zhou, 1999). According to the rule of the Qing Dynasty, the Han nationality and the Manchu nationality must live in different parts of the city. So it was crowded with the lower-class people in the outer city of the south. Recorded in Langqian Notes (Mandarin: lang qian ji wen chu bi, which was compiled in the Qing Dynasty and recorded the social cultures and customs at that time), commercial prosperity was further boosted, "the east locates the cloth and millet markets, the west locates the horse and charcoal markets, the south locates the poultry, birds and flowers markets, and the middle locates the jewelry and jade markets." In the late Qing Dynasty, turmoil in politics caused major commercial changes, and modernization of commerce gradually evolved. In the records of Research of Beijing, Peking's city space expanded further in the early Republic of China, and laid the basic pattern of today's commercial blocks in the ancient city. In modern times, commercial centers were once in dilemma due to the war; however they faced new opportunities and challenges after the establishment of the People's Republic of China (1949), especially in the Reform and Opening-up Period (1978-). The tremendous change of the political system, the social culture and the economic life has an important influence on the spatial distribution and hierarchical system of the commercial centers in the ancient city.

Predecessors conducted a detailed study on the historical geography of Beijing, which laid the foundation for its commercial space research. Edited in the Qing Dynasty, Records of Alleys in Beijing, Langqian Notes, The Old Tales Research (Mandarin: ri xia jiu wen kao, which was compiled in 1788 during the reign of Emperor Qianlong (1736-1795) and was the most detailed official historical records of Beijing in the Qing Dynasty), and Records of Cities and Walls recorded the historical evolution, scenic beauty, governmental offices, celebrities' former residences, and guild halls, etc. Among them, the appendixes of Records of Cities and Walls included detailed maps of the inner city, the outer city and suburbs, which played an important role in the study of ancient Beijing city's commercial blocks in the 
Ming and Qing dynasties. Edited in the late Qing Dynasty, Research of Beijing was a comprehensive and systematic account of the shift from ancient Beijing to the early Republic of China. Since modern times, the research on the Beijing city pattern in the Ming and Qing dynasties was represented by the works of Hou Renzhi, including Beijing History (1980), Beijing Historical Atlas (1988), Beijing City Historical Geography (2000), The Life Mark of Beijing City (2009), which elaborated the origin and evolution of Beijing city. In virtue of the Central Place Theory, Gao (1989) and Yang (1994) proved that the six major commercial centers in Beijing urban area occupy the six vertexes of a regular hexagon and form an attracting area with a smaller regular hexagon. The core of commercial in ancient Beijing city includes the districts of Xidan, Wangfujing and Qianmen and radiates outward, basically in line with the characteristics of the Central Place Theory. Wu et al. (2001) constructed the index system of commercial center and classified the levels of the ancient city commercial center, and proposed transportation, urban planning, population distribution and historical legacy as the motivation for the change of commercial center in the historical evolution. Sheng et al. (2013) studied the influence of traditional transportation mode and movement hierarchy on the distribution of commercial centers and verified that in historic cities, the layout of commercial centers relied on the relationships between different motion hierarchical networks rather than the simple closeness to the city gates.

\subsection{Relationship between commercial blocks and street network}

The efficient operation of city functions depends on the overall space network, while the street network is the basis of urban economic activity and land use (Hillier, 1996). Studying the Cambridge District, Massachusetts, Sevtsuk (2010) found that the characteristics of the endogenous spatial agglomeration possessed by commercial development are affected by the exogenous factors of land use patterns, planning, etc. Therefore, the street network plays the roles of space carrier, circulation corridor, driving factor, etc., of commercial blocks (Shen et al., 2015), and influences their layout structure as well as the hierarchical system.

The network characteristics of traffic elements have gradually become the focus of research for the evolution of urban commercial blocks. The influence of street networks on commercial spaces can be divided into the following three aspects. (1) The topological structure of the street network, especially accessibility and connectivity, is an important contributory factor for the layout of commercial blocks. Generally, higher accessibility and connectivity lead to a stronger commercial aggregation. In the global context, the gathering of shopping centers, retail outlets, and so on, with high accessibility has gradually become a trend (Hossain, 2014). Not only are the destination-targeted primary commercial activities attractive enough, but also secondary activities like retail categories, which live solely on the need of passers-by for good accessibility (Porta et al., 2012). Scoppa and Peponis (2015) pointed out that the improvement of street network accessibility is conducive to the promotion of commercial aggregation and spatial attraction. The centrality of the streets plays an important role in capturing the advantageous location of the city and shaping the intensity of commercial land use within the city (Wang et al., 2011). After comparing the relationship between the distribution of ten retail centers and street network patterns in London, Chiaradia et al. (2012) found that in such places the street integration and value of the center are better, and the value of the peripheral can be promoted accordingly. (2) The level of the 
street network affects the establishment of the hierarchy for commercial blocks, and there is a positive correlation between them. Sheng (2012) analyzed the spatial configuration of local shops within 222 urban blocks in the Third Ring Road of Beijing by using spatial syntax. From his analysis of traffic level and topological structure, he pointed out that the mutual superposition and supplementation of high-level transportation and low-level streets strengthens the agglomeration effect of commercial shops. In a study of the commercial blocks of ancient Beijing city, Sheng (2011) proposed that the formation of commercial blocks relies on the traffic structure, with high-level streets more easily creating an agglomeration of commercial activity, which thus promotes the formation of commercial blocks. (3) With the development of modern transportation modes, public transportation networks, such as BRT (Cervero and Kang, 2011), subways (Zhang et al., 2014), rail transit (Hong et al., 2015), etc., gradually changed the layout and level of commercial blocks. By using the elements of the transport network to build an integration model of retail spaces, Tsou et al. (2013) found that the distribution of retail patterns relies more on local accessibility and the bus network system in Taipei, and predicted that the subway network will strengthen the aggregation effect of retail patterns in the future. Based on the data of commercial districts and the subway network around the 15 subway stations in Guangzhou, Wang et al. (2015) proposed that there is a greater correlation between subway passenger flow and higher-level commerce. Commercial properties change from traditional retail to those that are more advanced in form and scale, mainly thanks to the increased crowd-flow. Thus, the cohesion and extension of commercial blocks are closely related to the development of the street network, and their layout structure and level adjustment vary with changes in the topological structure, hierarchy, and transportation type of the street network.

\subsection{Applicability of space syntax to the study of commercial blocks}

Spatial syntax is widely used in the evolution analysis of street networks and city spatial structure. The interrelated centers at each level on all scales constitute the foreground network, which reflects the degree of activeness of economic activities. This is because they are always seeking to maximize spatial accessibility (integration) and traffic flow (crossing ability) across the space. It has been found that the integration core/foreground network of space syntax is generally the center of urban centrality (Li et al., 2015). Commercial facilities are usually arranged in this location (Wu et al., 2015). The different mechanisms whereby street networks are generated may lead to a similar street hierarchy, whether it is an ancient city or a new one (Nahid and Agust, 2014). According to their analysis of the ancient city of Kasisi, Giannopoulou et al. (2012) found that the urban commercial and administrative functional centers are at the integration core of the street network, and residential areas with low accessibility. The applicability of spatial syntax in studying the relationship among the layout of commercial blocks, the street center, and topological structure has been verified in empirical studies of Barcelona, Spain (Porta et al., 2012), Changchun, China (Wang et al., 2014), etc. At the same time, according to the relationship between the street network structure and the commercial blocks shown by the space syntax, guidance can be provided for the expansion of commercial blocks in the future (Nayeem et al., 2015).

This study selected ancient Beijing city as a typical case for analysis by applying spatial syntax. We aimed to explore the following: (1) the deep structure characteristics and evolu- 
tionary laws of commercial blocks and street network in different periods from the Yuan Dynasty to the present; and (2) the functional mechanism whereby the form, structure, and traffic mode of the street network influence the formation and evolution of commercial blocks. In addition, further consideration was given to the following: (1) the influence of urban centripetal-centrifugal structural transformation on the structure of commercial blocks; (2) the stage development from mutation node to smooth development during the evolution of commercial blocks; and (3) the adaptation of traditional commercial blocks to the needs of a modern city, which aimed to understand the synergetic relationship between commercial blocks and urban development, and provided references for future commerce and city development.

\section{Data and study methods}

\subsection{Research area}

The pattern of ancient Beijing city, which is based on the Mid-capital of the Jin Kingdom and the Great Capital of the Yuan Dynasty, has been formed through the renovation and expansion of the Ming and Qing dynasties. The outline of the ancient city switched in form from rectangular to convex. It has mainly inherited and extended the street pattern, architectural form, and spatial order of the Ming and Qing dynasties. In this study, the Great Capital of the Yuan Dynasty was taken as the study scope during the stage of Yuan Dynasty. Regarding the boundary of ancient Beijing city from the Ming and Qing dynasties until today, the definition in the Master Planning of Beijing (2004-2020) is widely adopted, which is the city area including and within the ancient Beijing moat and ruins during the Ming and Qing dynasties: i.e., an area of approximately 62.5 square kilometers within the range of the Second Ring Road (Figure 1).

\subsection{Study method}

The segment model of space syntax was selected to abstract and model the space relationship. Combining the distance method of Normalising Least Angle Choice put forward by Hillier et al. (2012) with the operational method proposed by Turner (2007), two core variables, the NAIN (Normalized Angular Integration) and $\mathrm{NACH}$ (Normalized Angular Choice), were used.

(1) Integration indicates the extent of the distance from one street to other streets in the study area, describing the "centrality" of the street (the potentiality of to-movement), which can be understood as the street's topological accessibility. The calculation formula is as follows:

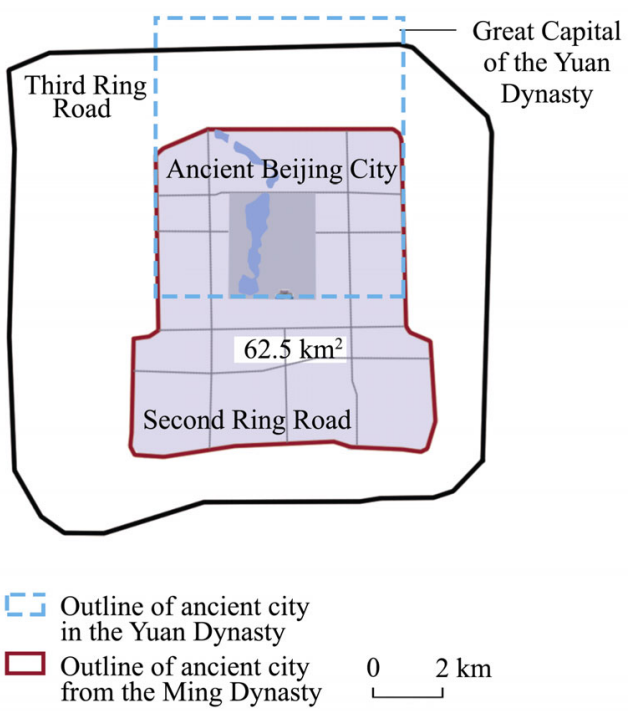

Figure 1 Location of the study area (Source: Authors) 


$$
\mathrm{NAIN}_{\mathrm{R}}=\frac{\mathrm{NC}_{\mathrm{R}}^{1.2}}{\text { Atotal depth }}
$$

where $\mathrm{NAIN}_{R}$ is the normalized angular integration, $\mathrm{NC}_{\mathrm{R}}$ is the number of nodes that are included within a range of measurement that adopts the central point of the study segments as the center of a circle. Atotal depth $\mathrm{R}$ is the depth, while $\mathrm{R}$ is the metric radius.

(2) Crossing choice indicates the probable frequency that the street is crossed by any other two streets as the shortest path, describing the street's "possibility of being traversed or commuting" (the potentiality of through-movement). This can be understood as the commuting capacity of the street: that is, the capacity to carry traffic flow. The calculation formula is as follows:

$$
\mathrm{NACH}_{\mathrm{R}}=\frac{\log \left(\text { Achoice }_{\mathrm{R}}+1\right)}{\log \left(\text { Atotal depth }_{\mathrm{R}}+3\right)}
$$

where $\mathrm{NACH}_{\mathrm{R}}$ is the normalized angular choice, Achoice $\mathrm{R}_{\mathrm{R}}$ is the choice of the angle, Atotal $\operatorname{depth}_{\mathrm{R}}$ is the depth, and $\mathrm{R}$ is the metric radius.

Higher integration degree and crossing choice represent better street performance and higher hierarchy, with a greater function of urban layout and traffic flow. In addition, the integration/choice core (the value of the top $5 \%$ of streets), foreground network (the value of the top $20 \%$ of streets), background network (the value of the bottom $80 \%$ of streets), and other variables are used to describe the relationship between the street network and evolution of commercial blocks in ancient Beijing city.

\subsection{Data acquisition and processing}

\subsubsection{Data acquisition and processing of street network}

The time interval of the study ranged from the Yuan Dynasty until today. The time was selected when data collected from the commercial layout were consistent with the period of the map space syntax data. Taking into account elements of the commercial blocks in the ancient city, including the layout, map information, cartographic accuracy, etc., as well as the turning period of these commercial blocks, maps of six important periods were selected. Thus, the years 1341-1368 (during the Zhizheng periods of the Yuan Dynasty), 1573-1644 (during the Ming Dynasty, the reigns from Emperor Wanli to Emperor Chongzhen), 1907 (during the Qing Dynasty Emperor Guangxu's reign), 1936 (during the Republic of China), 1976 (during the exploration period of the People's Republic of China), and 2013 (the reform and opening-up period of the People's Republic of China) were used as the objects of the spatial syntax analysis. Furthermore, ArcGIS was used for correcting deviations and georeferencing, while CAD was used for mapping. The information was then imported into Depth map, and a segment model was generated. The topological datasets were then established. After using GISMAP to transform the format, all six maps were entered into ArcGIS. Finally, the syntactic parameters of the street network were classified and the collected data were stacked up at various periods for further analysis (Figure 2). The study data of ancient Beijing city were drawn from the following ancient books: (1) Records of Cities and Walls (2) Records of Alleys in Beijing; (3) Research of Beijing; (4) Rites of the Zhou Dynasty; (5) The Records of Examination of Craftsman; (6) Langqian Notes; (7) The Old Tales Research. 


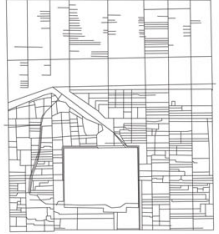

(a) Yuan Dynasty (1271-1368)

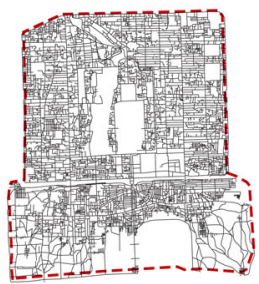

(d) Republic of China (1912-1949)

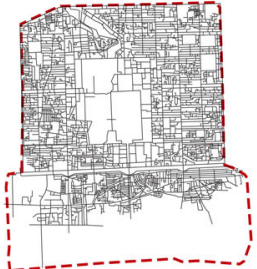

(b) Ming Dynasty (1368-1644)

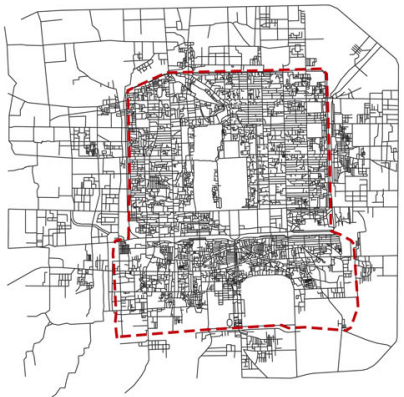

(e) Exploration Period of the People's Republic of China (1949-1977)

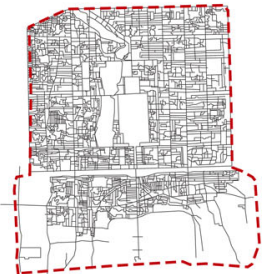

(c) Qing Dynasty (1644-1911)

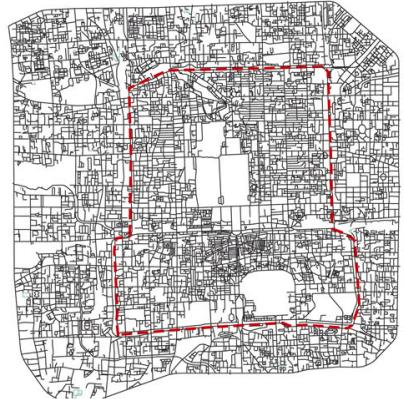

(f) Reform and Opening-up Period of the People's Republic of China (1978-)

City wall of the Ming Dynasty (1368-1644)

Figure 2 The segment model of spatial syntax at various periods (Source: Figures were redrawn by the authors based on the originals from the following sources: a-c. Wang, 2011; d. Hou, 1988; e. Beijing Geological and Topographic Survey Department, 1976; f. Google Earth, 2013)

\subsubsection{Data acquisition and processing of commercial blocks}

Based on the relevant literature, we summarized the commercial blocks of various periods in ancient Beijing city as shown in Figure 3. According to the literature description of commercial scale, number, radiation range, service group, function orientation of each period, and combining with the grading system, the commercial blocks of the ancient city were divided into three levels, i.e., the first, second, and third levels. From the Ming and Qing dynasties to the period of the Republic of China, some large temple fairs sprang up and agglomerated as commerce with mobility, which have an important influence on the city commercial pattern as the fourth commercial levels were analyzed (Table 1).

\section{Evolution of commercial blocks in ancient Beijing city}

Using Depthmap, we calculated the street

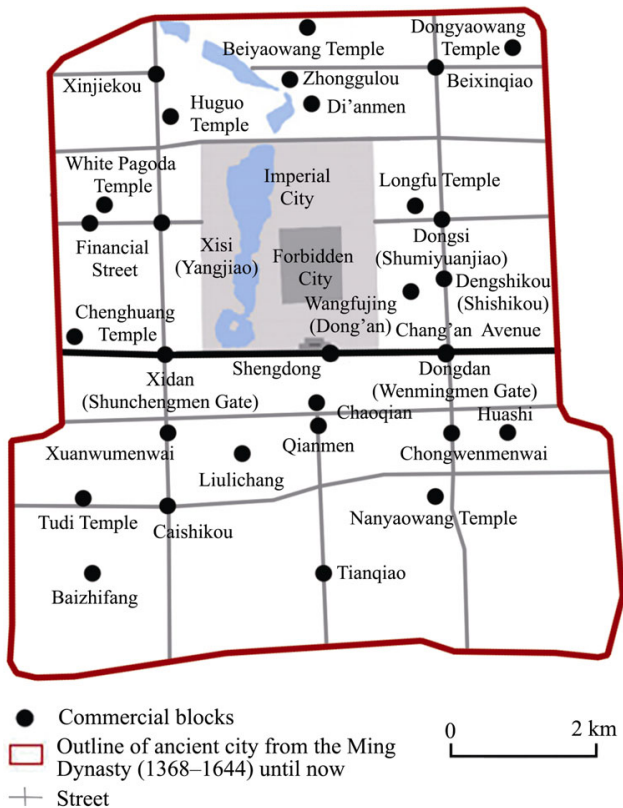

Figure 3 Summary of the commercial blocks of ancient Beijing city in different periods (Source: Authors) 
Table 1 Summary of the commercial blocks of ancient Beijing city in different periods

\begin{tabular}{|c|c|c|c|c|}
\hline \multirow[b]{2}{*}{ Period } & \multicolumn{4}{|c|}{ Level of commercial blocks } \\
\hline & First level & Second level & Third level & $\begin{array}{l}\text { Fourth level } \\
\text { (Temple fair) }\end{array}$ \\
\hline $\begin{array}{l}\text { Yuan Dynasty } \\
(1271-1368)\end{array}$ & $\begin{array}{l}\text { Zhonggulou } \\
\text { Block }\end{array}$ & $\begin{array}{l}\text { Yangjiao Block, } \\
\text { Shumiyuanjiao } \\
\text { Block }\end{array}$ & $\begin{array}{l}\text { Shengdong Block, Shun- } \\
\text { chengmen Gate Block, } \\
\text { Shishikou Block, Wen- } \\
\text { mingmen Gate Block }\end{array}$ & \\
\hline $\begin{array}{l}\text { Ming Dynasty } \\
(1368-1644)\end{array}$ & $\begin{array}{l}\text { Chaoqian } \\
\text { Block }\end{array}$ & $\begin{array}{l}\text { Dengshikou Block, } \\
\text { Xisi Block }\end{array}$ & $\begin{array}{l}\text { Di'anmen Gate Block, Xin- } \\
\text { jiekou Block, Beixinqiao } \\
\text { Block, Dongsi Block, } \\
\text { Dongdan Block, Xidan } \\
\text { Block, Caishikou Block, } \\
\text { Chongwenmenwai Block }\end{array}$ & Chenghuang Temple \\
\hline $\begin{array}{l}\text { Qing Dynasty } \\
(1644-1911)\end{array}$ & $\begin{array}{l}\text { Qianmen } \\
\text { Block }\end{array}$ & $\begin{array}{l}\text { Dongsi Block, } \\
\text { Chongwenmenwai } \\
\text { Block, Xisi Block, } \\
\text { Caishikou Block }\end{array}$ & $\begin{array}{l}\text { Di'anmen Gate Block, } \\
\text { Dongdan Block, Xidan } \\
\text { Block, Dong'an Block, } \\
\text { Liulichang Block, Tianqiao } \\
\text { Block, Huashi Block, } \\
\text { Beixinqiao Block, Xinjiekou } \\
\text { Block }\end{array}$ & $\begin{array}{l}\text { Longfu Temple, Hu- } \\
\text { guo Temple, Chen- } \\
\text { ghuang Temple, Bei- } \\
\text { yaowang Temple, } \\
\text { Tudi Temple, Nan- } \\
\text { yaowang Temple, } \\
\text { Dongyaowang Temple }\end{array}$ \\
\hline $\begin{array}{l}\text { Republic of China } \\
(1912-1949)\end{array}$ & $\begin{array}{l}\text { Wangfujing } \\
\text { Block, } \\
\text { Qianmen } \\
\text { Block }\end{array}$ & $\begin{array}{l}\text { Dongsi Block, Xisi } \\
\text { Block, Dongdan } \\
\text { Block, Xidan Block, } \\
\text { Chongwenmenwai } \\
\text { Block, Caishikou } \\
\text { Block, Tianqiao } \\
\text { Block }\end{array}$ & $\begin{array}{l}\text { Xinjiekou Block, Beixinqiao } \\
\text { Block, Di'anmen Gate } \\
\text { Block, Liulichang Block, } \\
\text { Huashi Block }\end{array}$ & $\begin{array}{l}\text { Huguo Temple, } \\
\text { Dongyaowang Tem- } \\
\text { ple, White Pagoda } \\
\text { Temple, Longfu Tem- } \\
\text { ple, Tudi Temple, } \\
\text { Nanyaowang Temple }\end{array}$ \\
\hline $\begin{array}{l}\text { Exploration Pe- } \\
\text { riod of the Peo- } \\
\text { ple's Republic of } \\
\text { China } \\
(1949-1977)\end{array}$ & $\begin{array}{l}\text { Xidan Block, } \\
\text { Wangfujing } \\
\text { Block, } \\
\text { Qianmen } \\
\text { Block }\end{array}$ & $\begin{array}{l}\text { Dongsi Block, Xisi } \\
\text { Block, Caishikou } \\
\text { Block, } \\
\text { Chongwenmenwai } \\
\text { Block, Tianqiao } \\
\text { Block }\end{array}$ & $\begin{array}{l}\text { Xinjiekou Block, Beixinqiao } \\
\text { Block, Di'anmen Gate } \\
\text { Block, Xuanwumenwai } \\
\text { Block, Baizhifang Block, } \\
\text { Liulichang Block }\end{array}$ & \\
\hline $\begin{array}{l}\text { Reform and } \\
\text { Opening-up } \\
\text { Period of the } \\
\text { People's Republic } \\
\text { of China (1978-) }\end{array}$ & $\begin{array}{l}\text { Xidan Block, } \\
\text { Wangfujing } \\
\text { Block, } \\
\text { Qianmen } \\
\text { Block }\end{array}$ & $\begin{array}{l}\text { Financial Street, } \\
\text { Dongsi Block, } \\
\text { Chongwenmenwai } \\
\text { Block, Xuan- } \\
\text { wumenwai Block }\end{array}$ & $\begin{array}{l}\text { Xinjiekou Block, Beixinqiao } \\
\text { Block, Di'anmen Gate } \\
\text { Block, Xisi Block, Baizhi- } \\
\text { fang Block, Caishikou } \\
\text { Block, Tianqiao Block }\end{array}$ & \\
\hline
\end{tabular}

Source: The table was compiled by the authors based on the related reference information: Fan, 2008; Gao, 1989; Hou et al., 2000; Qi, 2011; Qi et al., 2014; Sheng et al., 2013; Wu et al., 2016; Wu et al., 2001; Zhang, 2009.

network syntax parameters of segment model diagrams in different periods. With ArcGIS 10, the data of commercial blocks were overlapped to conduct spatial analysis. (1) In space syntax measurement, the set global radius is $\mathrm{n}$ and the local radius is $1600 \mathrm{~m}$ (a travel distance of $20 \mathrm{~min}$ on foot or $10 \mathrm{~min}$ by bike). Global integration $(\mathrm{R}=\mathrm{n})$, local integration $(\mathrm{R}=1600$ $\mathrm{m})$, global crossing, and local crossing were selected as the parameters of the street network syntax. (2) The scope of commercial blocks was centered at the core location of a commercial block (mostly the intersections of main streets) with a diameter of $800 \mathrm{~m}$ (radiation range of the third-level commercial blocks in general). The average value of the corresponding syntactic parameter of the street foreground network within the scope was calculated relevantly as the syntax parameter of commercial block (Figure 4). 


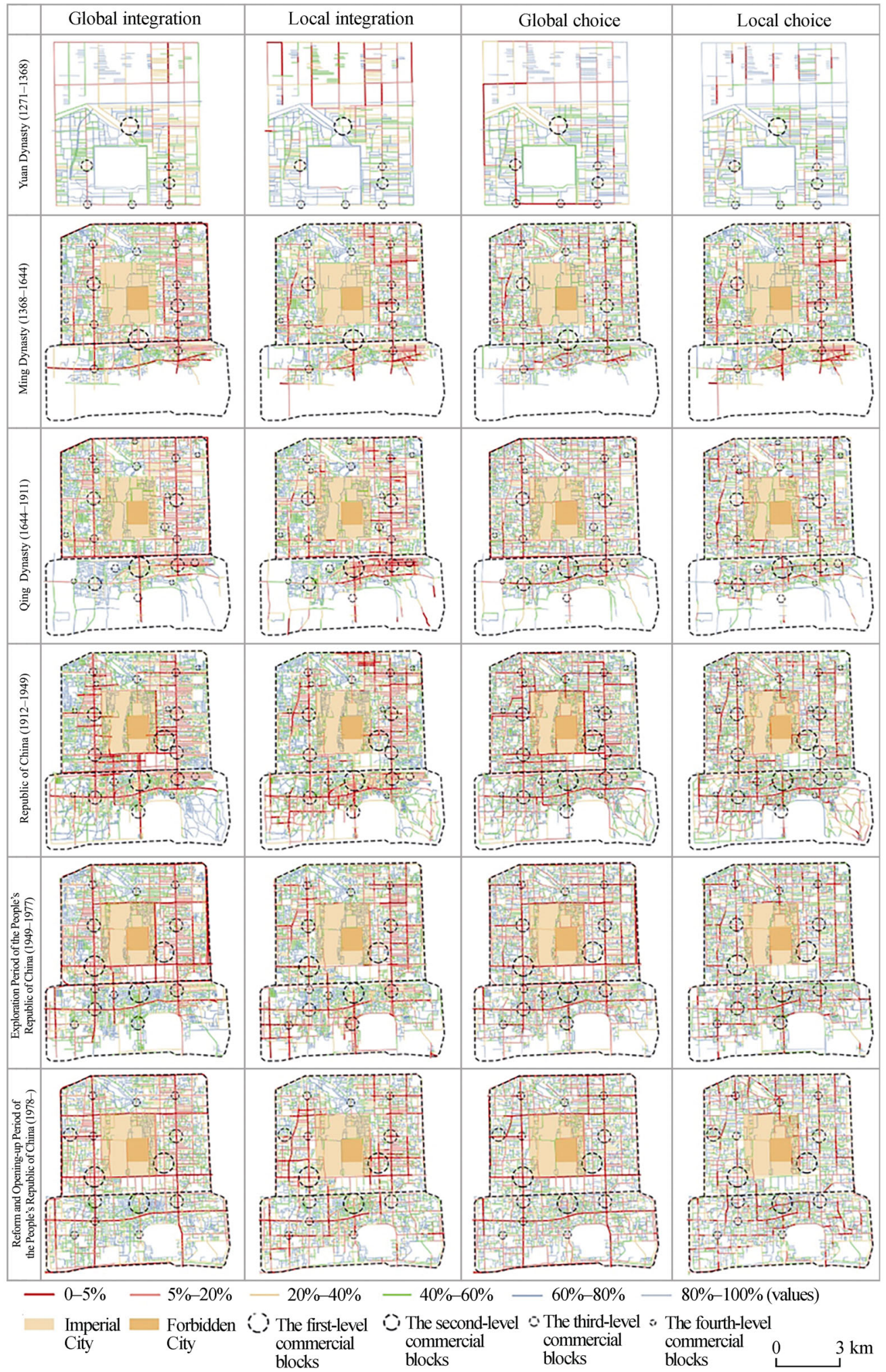

Figure 4 Evolution of the commercial blocks and street network in different periods (Source: Depthmap and ArcGIS analysis) 


\subsection{Foundation period in the Yuan Dynasty (1271-1368): Integrated palace-market system}

In the Yuan Dynasty, the commercial blocks were formed. The feature of the stable commercial structure was the palace in front with market behind. During this period, the development of the inner-city network promoted the aggregation of economic activities and population (Wang et al., 2015). The commercial blocks were arranged symmetrically around the imperial palace and matched the features of the street network (Figure 4). (1) The distribution of commercial blocks was highly matched with the main streets that possessed high integration and choice degrees. Commercial blocks were located in the chessboard-shaped north-south or east-west main streets that connected the city gates, so that the formation of commercial blocks was attached to the overall network with high accessibility and commuting ability. (2) There was isolation between the eastern and western streets, as well as the "East superior to West" street network pattern that made commerce on each side closed and isolated. As a result, the commercial scale and quantity of the eastern part was better than that of the western in Beijing. (3) The distribution of commercial blocks did not match the local integration degree or choice degree, which indicated that the commercial blocks were less dependent on the accessibility and commuting efficiency of the local area. The local crowd gathering effect was weak. (4) The gates' effect was prominent. Due to the convenience of traffic and goods commodity, the gates finally became the commerce gathering points.

\subsection{Initial development period in the Ming Dynasty (1368-1644): East over west in symmetrical axis}

The pattern of commercial blocks was basically formed in the Ming Dynasty, showing a symmetrical axis with East superior to West. As the commercial layout spread southward in this period, the "palace-market" limitations for commerce were broken. The overall development of the street network not only increased the number of commercial blocks and promoted their levels, but several new commercial blocks were also developed on the layout basis of the Yuan Dynasty (Figure 4). (1) The locations of commercial blocks were perfectly matched with the U-shaped structure, consisting of core integration degree and choice degree streets. An axial symmetrical structure emerged in which the commercial blocks were distributed along the two north-south main streets centered on the imperial city. (2) Due to the optimization of local traffic structure, the commercial blocks tended to match the integration center in the local scale, especially the newly added blocks that had a strong advantage in terms of local accessibility but not in local choice. (3) The number of commercial blocks was consistent with the development of the street network. In fact, in the inner city, the commercial density of the eastern part was higher than that of the western. Furthermore, commerce in the outer city was still in the budding stage and commerce here was far less in number and scale than in the inner city.

In this period, new commercial blocks were more likely to locate in segments with high global accessibility and high commuting efficiency, and gradually began to rely on the accessibility of local areas. At the same time, the positive correlation between commercial blocks and the development level as well as the hierarchical system of the traffic network was gradually clarified. 


\subsection{Drastic adjustment period in the Qing Dynasty (1644-1911): South over north in symmetrical axis}

During the Qing Dynasty, the commercial blocks experienced a dramatic adjustment stage. The symmetry of the axial structure weakened, showing a commercial structure of "South superior to North" (Figure 4). The Qing Dynasty intended to implement a commerce prohibition policy in the inner city. While this policy destroyed the commerce in the inner city at that time, the rise and prosperity of commerce in the outer city were promoted. After the mid-Qing Dynasty, inner city commerce became warmer due to a slack policy. From the layout of the commercial blocks, we found: (1) because of the Qing Dynasty structure of "double political centers" and the opening of the imperial city, the symmetry of commercial blocks' distribution was alleviated. (2) The layout of commercial blocks in the inner city was similar to that of the Ming Dynasty, and was symmetrical along the central axis of the north and south main streets with high integration and choice degrees. The Dong'an Block developed, relying on its accessible traffic. (3) The number of commercial blocks in the outer city increased rapidly, and was matched with the local integration center and choice center. (4) The rise of temple fairs greatly complemented the commercial structure. Generally, these large temple fairs were located close to the ancient city walls and the second-level commercial blocks. It was obvious that they relied on the traffic structure and played a role as sub-commercial centers to serve the whole city.

Considering the level changes of commercial blocks, the "South superior to North" structure appeared. (1) The first-level commercial blocks transferred from the chessboard streets to the Qianmen Block. On the one hand, any commerce was forbidden in the inner city; on the other, the construction of Qianmen Railway Station attracted people and goods to accumulate in the Qianmen Block. Thus, the Qianmen Block soon became the largest commercial block. (2) At the same time, the prosperity of the Qianmen Block led to the upgrading of the Caishikou Block and Chongwenmenwai Block. In particular, the Chongwenmenwai Block was the integration and choice center in the outer city, showing an "East rich and West flourish" living pattern in the outer city; in the inner city, the Dongsi Block was able to compete with the Xisi Block and became the second-level commercial block after the transfer of the lantern market and the optimization of its own traffic structure. (3) The layout of the third-level commercial blocks in the inner city remained basically unchanged, while their numbers increased in the outer city. Moreover, the emergence of temple fairs expanded the commercial influence and service capabilities of the outer city, which made it a veritable city economic center.

During this period, the commercial blocks basically occupied the center of the city streets, particularly matched with high local integration and choice degrees. With the increase in accessibility and commuting ability of the core streets, the Qing Dynasty commercial blocks were more dependent on local scale topological accessibility and short distance commuting efficiency in the whole city.

\subsection{Further change in the Republic of China (1912-1949): Double-center structure}

The period of the Republic of China was the stage of most coincidence between traffic centers and commercial blocks. The locations of commercial blocks were almost unchanged 
from the Qing Dynasty, but there was significant promotion in each level. Numerous commercial blocks in the first and second levels appeared and gathered in the ancient city center. This all contributed to the present basic pattern of Beijing's commercial blocks (Figure 4). (1) Due to its unique location in the eastern outskirts of the embassy area and the input of foreign investment, the original Dong'an Block developed into the first-level commercial block in the Wangfujing Block. With the development of Wangfujing Block, the axial symmetrical structure of commerce in the Forbidden City was broken and a double-center multi-level commercial block layout was formed. (2) With the connection of the East and West Chang'an Avenues, the accessibility and space attraction of the Xidan and Dongdan blocks in the inner city greatly improved, and they soon developed into the second-level commercial blocks. After the opening of the Temple of Heaven, the Tianqiao Block in the outer city strengthened the north-south traffic axis extension. At the same time, due to the influence of the capital moving to Nanjing, a city in southern China, the consumer groups in Wangfujing and Xidan transferred from a privileged stratum to civilians, and the Tianqiao Block became the largest civilian market in the outer city. (3) The locations of the third-level commercial blocks had barely changed. Compared to the second-level center, their topological structure was not sufficiently accessible with lower spatial attractiveness. (4) As the fourth-level commercial blocks, temple fairs still relied on the second- and third-level commercial blocks. Due to the civilian-targeted feature, the temple fairs would not appear in the high-end consumption blocks like the Wangfujing, Xidan, and Qianmen.

With the popularity of trains, trams, and cars, the long-distance traffic network gradually came to play an increasingly important role. The spread of manpowered tricycles and bicycles also made the local walking space accessible. Moreover, the increased spatial attraction and commuting capability had contributed to the upgrading of the commercial blocks' level. At the same time, the moving of the capital caused the loss of Beijing royalty, the development of a civilian market, and a change in commercial attributes.

\subsection{Exploration period of the People's Republic of China (1949-1977): Tripar- tite-confrontation situation with center gathering}

In the exploration period of the People's Republic of China, the commercial blocks formed a tripartite confrontation structure. The higher-level commercial blocks still showed a center-gathering feature, but there was a trend of circular distribution (Figure 4). (1) The first-level Xidan Block occupied an absolute advantage in terms of accessibility and commuting ability. Due to their profound historical accumulation and commercial basis, the Wangfujing Block and Qianmen Block continued as the first-level commercial blocks. (2) The second-level commercial blocks had a stronger advantage in global and local integration and choice degrees, which showed that accessibility and long-distance transportation had gradually became the dominant factors in the layout of commercial blocks. (3) The third-level commercial blocks, such as the Xinjiekou Block and Di'anmen Gate Block, despite having an advantage in terms of traffic position, were weak in the competition with the Xidan Block, Wangfujing Block, and other large commercial blocks. Furthermore, the development of the ancient city was southward but not northward; so their commercial grade was not promoted. There was a positive correlation between the level of the commercial blocks and traffic parameters in this period, but this gap gradually narrowed. This showed 
that in the process of enhancing city accessibility and commuting ability, the reliance on traffic to determine the commercial block level decreased.

During this period, the increasing number and hierarchical arrangement of commercial blocks conformed to the direction of urban expansion indicated by the street network. With the removal of the ancient city walls and the development of street networks, commercial blocks increasingly paid attention to accessibility and commuting ability. While commercial level and street network hierarchies were clearer, the numerical gap was narrowing.

\subsection{Reform and opening-up period of the People's Republic of China (1978-): Tripar- tite-confrontation situation with circular distribution}

The commercial blocks of the reform and opening-up period still maintained the tripartite-confrontation structure. At the same time, circular distribution in the ancient city was more obvious, showing that the higher-level commercial blocks gathered at the center with the lower levels at the fringe (Figure 4). (1) Due to the construction of subways and streets, the Wangfujing and Xidan blocks were still located in the street center as the first-level commercial blocks. The Qianmen Block gradually lost its central position with poor street conditions in the process of street traffic development. However, because of its historic and cultural heritage, the Qianmen Block maintained a high vitality, and its tourism attraction increased. (2) The biggest change in the second-level commercial blocks was the construction of the Financial Street. This street occupied a superior traffic area with high accessibility and choice degree, and somehow weakened the influence of the Xisi Block, leading to the downgrading of this block. In addition, the Xuanwumenwai Block was developing on the basis of the ancillary functions and high traffic level of the first-level commercial blocks. (3) The influence of the original second-level commercial blocks, such as the Caishikou Block and Tianqiao Block, gradually waned. For the lower level commercial blocks, their traffic advantages could not prevent the reduction in competitiveness and consumption due to population suburbanization and commercial circle outward. Thus, the higher-level commercial blocks relied on their central location and gathered at this period. However, the lower level commercial blocks were fading out in the process of urban development.

During the development of the street network, local commuting capacity greatly improved, which promoted commercial development. However, the relationship between the commercial level and transportation level was not completely matched. Moreover, the narrowing of the traffic gap meant that commercial blocks faced the transition situation of introducing other vitality factors to stimulate space vitality.

\section{Evolution mechanism of commercial blocks in ancient Beijing city}

The evolution mechanism of commercial blocks involved two dimensions: first, the changing street network changed the spatial identifiability and accessibility, which were closely related to commercial development; second, the evolutionary traffic pattern had great impacts on the city layout and commercial structure.

\subsection{Influence of street network on commercial structure}

We adopted the two core variables of space syntax, the NAIN (Normalized Angular Integra- 
tion) and NACH (Normalized Angular Choice) to examine the relationship between street networks and commercial structure. While the angular integration can reflect the network synergy, the angular choice can reflect the network topological structure.

\subsubsection{Network synergy}

Street network synergy is the expression of the fitting degree and correlation between global and local integrations, i.e., regression coefficient $\mathrm{R}^{2}$. The integration uses spatial topological relations to infer the crowd-flow direction, so the fitting degree of local and global integration can represent the relationship between the part and whole structure in the way in which the synergy relationship exists between global and local centers. More specifically, a higher synergy degree means that local centers are better integrated into the overall city structure. With the understandable and recognizable space, the city center and local center locations tend to be consistent. For the city structure, it has a higher advantage in terms of the aggregation of global and local crowd-flow. The centripetal tendency of function is strong, and the network will form a single-center structure. In contrast, the lower synergy degree means the local space can be hardly comprehensible and identifiable. A separation phenomenon happens in the local center and city center. The city structure shows a strong force in the whole crowd-flow diversion and local crowd-flow aggregation. The centrifugal development of network function tends to be a multi-center structure. Therefore, by comparing the synergy degrees of the development between street network and commercial block in different periods, the evolution of commercial blocks can be further explained by the change in street network form.

The synergy between street networks and commercial blocks showed a positive correlation (Table 2), which meant that the urban street network structure had a positive correlation effect on commercial center layout. The centripetal development of a city promoted the clustering of commercial blocks, while a weakened centripetal function caused the corresponding commercial blocks to be discretely distributed. After observing the street network synergy of the first-level, second-level, and third-level commercial blocks in different periods, it was obvious that (Figure 5) (1) the first-level commercial blocks had a low synergy degree in the Yuan and Ming dynasties, but with a great impact, indicating that the development of the high-grade commercial blocks was not dominated by spatial attraction or crowd-flow gathering. However, since the beginning of the Qing Dynasty, the synergy degree and fitting degree have gradually increased. Although the highest synergistic interval was not occupied, but

Table 2 Synergy degree of commercial blocks grade and street network in different periods

\begin{tabular}{|c|c|c|c|c|}
\hline Period & $\begin{array}{l}\text { First-level } \\
\quad\left(R^{2}\right)\end{array}$ & $\begin{array}{l}\text { Second-level } \\
\left(R^{2}\right)\end{array}$ & $\begin{array}{l}\text { Third-level } \\
\quad\left(R^{2}\right)\end{array}$ & $\begin{array}{l}\text { Whole } \\
\left(R^{2}\right)\end{array}$ \\
\hline Yuan Dynasty (1271-1368) & 0.588 & 0.718 & 0.719 & 0.684 \\
\hline Ming Dynasty (1368-1644) & 0.443 & 0.966 & 0.890 & 0.898 \\
\hline Qing Dynasty (1644-1911) & 0.761 & 0.795 & 0.787 & 0.775 \\
\hline Republic of China (1912-1949) & 0.853 & 0.910 & 0.912 & 0.894 \\
\hline $\begin{array}{l}\text { Exploration Period of the People's Republic } \\
\text { of China (1949-1977) }\end{array}$ & 0.701 & 0.901 & 0.771 & 0.738 \\
\hline $\begin{array}{l}\text { Reform and Opening-up Period of the } \\
\text { People's Republic of China (1978-) }\end{array}$ & 0.678 & 0.884 & 0.831 & 0.812 \\
\hline
\end{tabular}


was always at the upper level, this indicated that the first-level commercial blocks gradually integrated into the city's overall structure with gradually increased spatial attraction and crowd-flow gathering. (2) The second-level and third-level commercial blocks in each period showed a similar situation that was always in the vicinity of the fitting line. The second-level commercial blocks occupied the best local-global inclusion area, followed by the third-level blocks. That was to say, the maintenance of the second-level and third-level commercial blocks relied on the high spatial identifiability and strong "local-global" ability to aggregate crowd-flow, showing a strong dependence on crowd-flow.
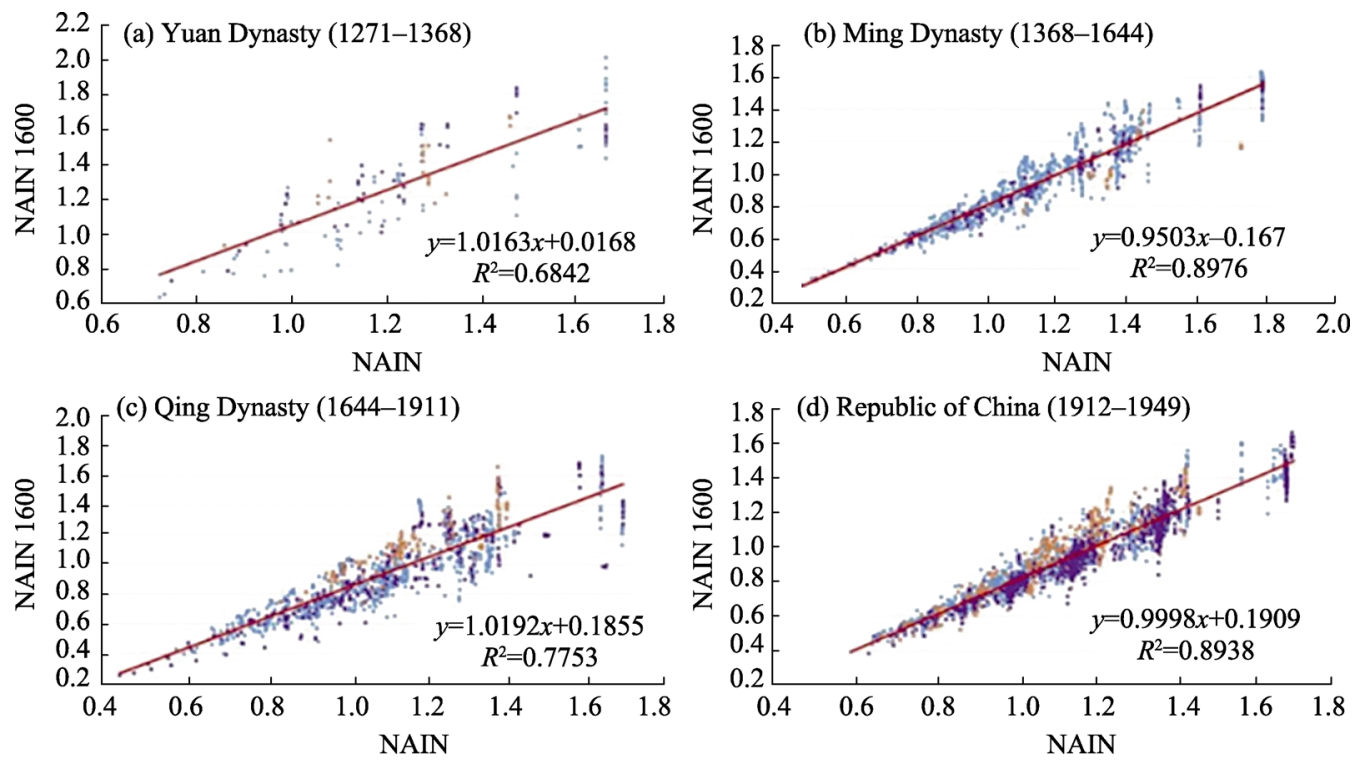

(e) Exploration Period of the People's
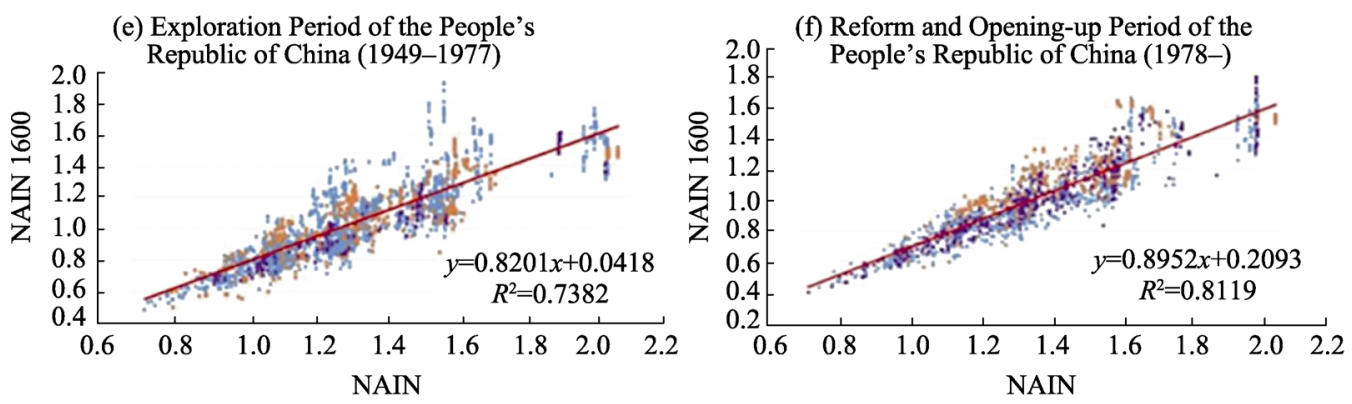

- The first-level commercial blocks - The second-level commercial blocks - The third-level commercial blocks

Figure 5 The synergy degree of commercial blocks and street networks in different periods (Source: Depthmap analysis)

\subsubsection{Network topological structure}

We further explored the influence of the surrounding street network topological structure on the evolution of commercial blocks, and discussed the relationship between the layout and hierarchy of the commercial blocks and the integration and choice degrees of street networks in different periods.

From the street foreground network (Figure 6), it could be seen that the ancient city's streets with high integration degree (living streets) and the high-pass streets with high crossing ability (commuting streets) were gradually converging and evolving into a homo- 


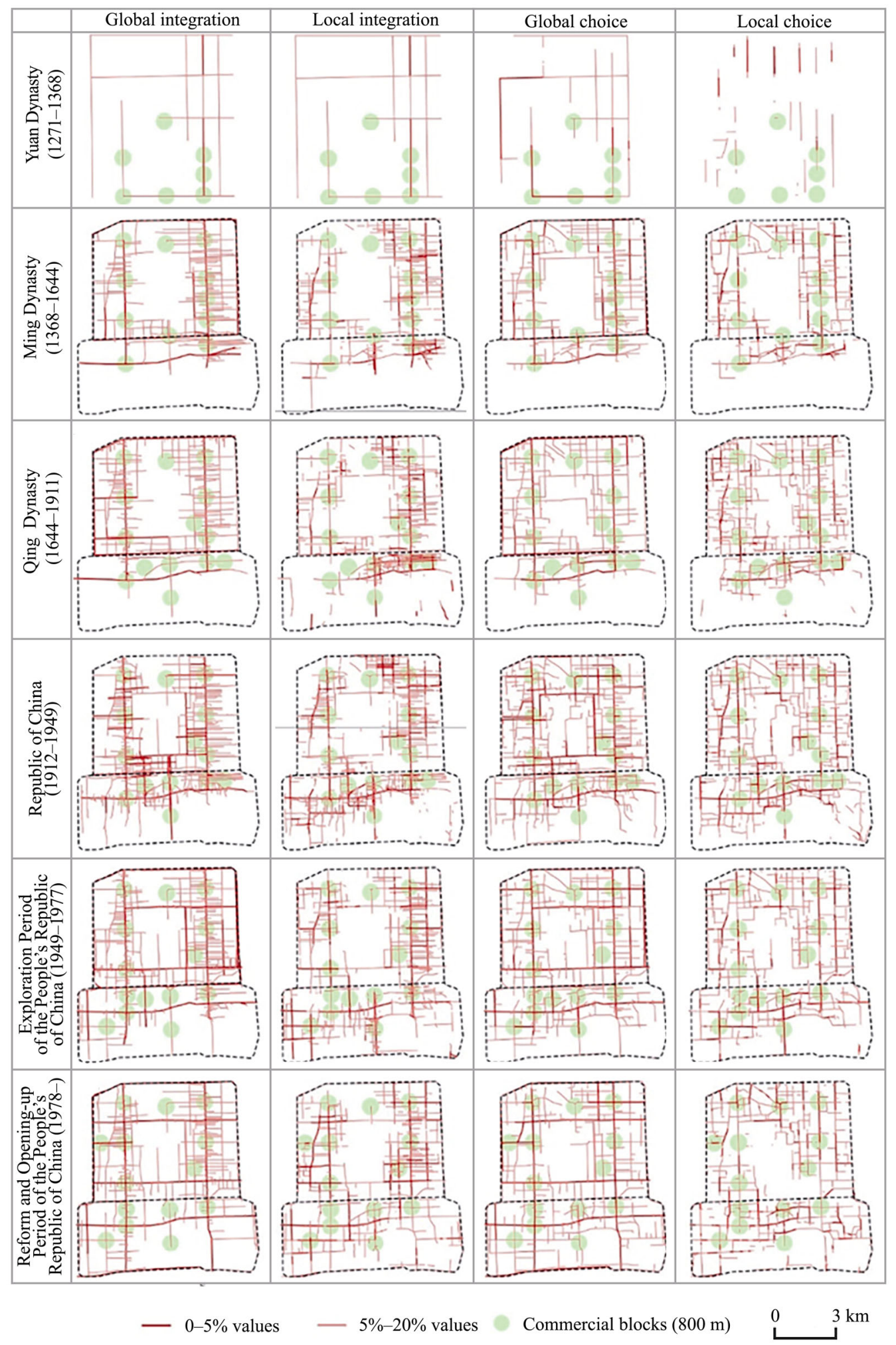

Figure 6 The evolution of commercial blocks $(800 \mathrm{~m})$ and street foreground network in different periods (Source: Depthmap and ArcGIS analysis) 
geneous street network. It showed that ancient Beijing city remained a constant speed system under the development of the modern rhythm, which differed from the automobile system in the development of the modern city. This situation was more suitable for the slower pace of life. At the same time, with the improved long-distance commuting efficiency, the accessibility and commuting efficiency of the local areas were also steadily increasing. With this development tendency of the street network, the dependence of commercial blocks' layout on the accessibility and commuting of the street network was also changing.

From the variation tendency of syntactic parameters of commercial blocks in each period (Figure 7), we found the following: (1) Variation tendency: the trend of syntactic parameters of commercial blocks was consistent with that of street networks in each period, and was greater than the average value of street networks, indicating that commercial blocks occupy the dominant location in the traffic structure. Commercial development and street network development were mutually reinforcing and interacting, and the development trend kept pace. (2) Global integration: commercial blocks in each period had a high global reachability.

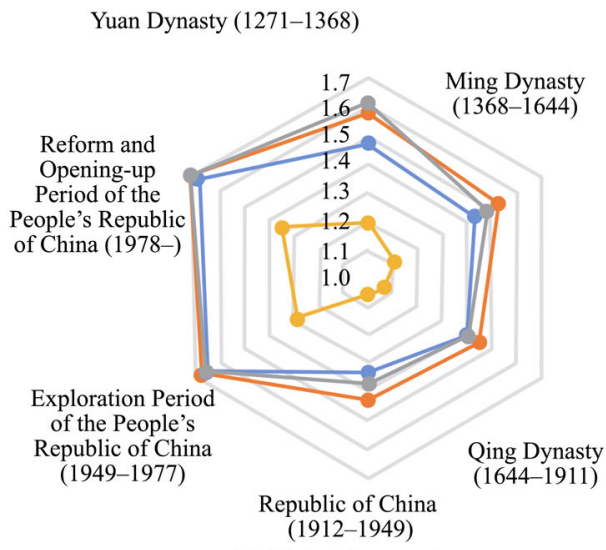

(a) Global integration

Yuan Dynasty (1271-1368)

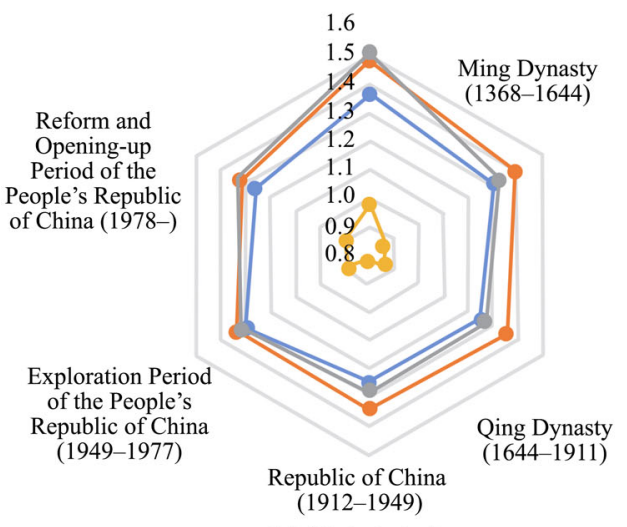

(c) Global choice

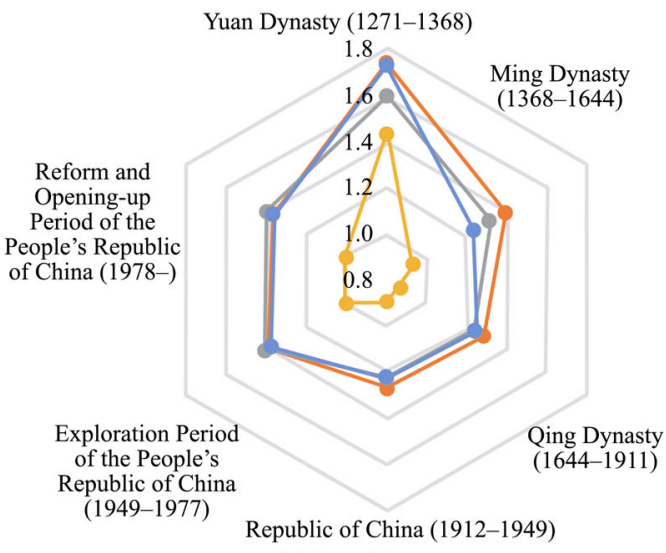

(b) Local integration

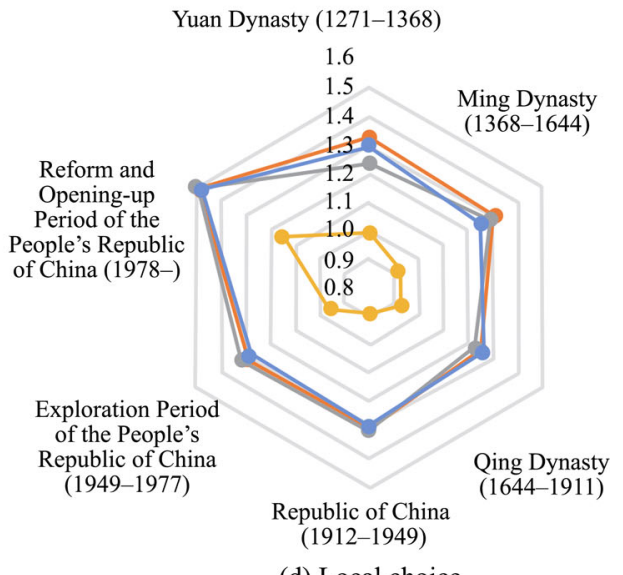

(d) Local choice

$\longrightarrow$ The first-level commercial blocks
$\longrightarrow$ The second-level commercial blocks

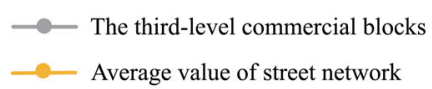

Figure 7 Change of foreground network parameters of commercial blocks and street networks in different periods (Source: Excel analysis) 
Especially since the establishment of the People's Republic of China, the accessibility of each commercial block has tended to be consistent. Therefore, the overall high accessibility was always a necessary condition for the development of commercial blocks. (3) Local integration: regarding the commercial blocks, the trend of local and global accessibility was similar. The hierarchy of local accessibility of the second-level and third-level commercial blocks was obvious in the Yuan, Ming, and Qing dynasties and in the Republic of China. When walking was the main transportation mode, commercial development was highly dependent on local accessibility. Areas with higher accessibility were more likely to attract commercial activities; during the change to modern transportation and street networks, the local accessibility level dependence weakened. (4) Global choice: the global choice of commercial blocks was higher than the average level of other street network parameters. Because of the commodity singularity and service limitations during the Ming and Qing dynasties, long-distance commuting efficiency was more important. During and after the Republic of China, the global choice degree has been greatly improved, which showed that changes in traffic patterns promoted long-distance commuting efficiency, and traffic flow has gradually become the major factor in commercial development. (5) Local choice: before the founding of the People's Republic of China, the local choice degree of different levels of commercial blocks remained relatively stable in different periods, indicating that the dependence of previous commerce on local commuting efficiency was not very high. Today, however, the short-distance commuting efficiency has been greatly enhanced, and has brought together more crowd-flow and traffic. Local area attractions and transportation capacity have become important factors in the development of commercial blocks, even more important than the impact of long-distance commuting.

Therefore, the high accessibility of the ancient city was a prerequisite for the location of commercial blocks. Based on walking and slow traffic, the Yuan, Ming, and Qing dynasties and the Republic of China had high local accessibility, which made the gathering of commercial activities easy; at the same time, more attention was paid to overall commuting efficiency. With the improvement of long-distance commuting efficiency, the dependence on local accessibility weakened, but local choice was reinforced.

\subsection{Role of traffic pattern changes in commercial blocks}

From the evolution process of commercial blocks and the topological structure of street networks, we can see that the second-level and third-level commercial blocks and traffic structure had a positive correlation, and the main traffic mode transformation could promote the change of the first-level commercial center layout.

The city form of ancient Beijing city has changed from closed to open. This involved a change from the enclosure space enclosed by city walls and gates to an open space strung with train, tram, and subway, accompanied by transportation changes and the modernization process (Figure 8). Before the Republic of China, due to the limitation of traditional transportation modes, including water transportation, carriages, and walking, and the spatial baffling caused by the ancient city gates and walls, the commercial blocks, especially the first-level ones, were located in the city center, occupied the location of transport hub nodes for goods, and showed a typical "location center" mode. With the demolition of the walls in modern times and the emergence of modern transport modes, the gathering capacity of the 
first-level and second-level blocks has been strengthened. Trams, buses, subways, and other high-intensity linear contact modes of transportation have weakened the dependence on specific space nodes, although commercial blocks still gathered at multi-traffic sites. As a result, the layout of commercial blocks has come to depend on the crossing ability of "commuting flow center" from "location center" mode. It was also further explained that the development of commercial blocks depended on accessibility in the early stage, while relying on commuting efficiency and traffic-carrying capacity later.

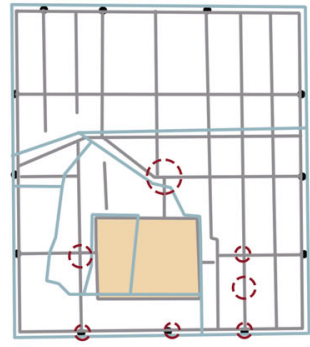

(a) Yuan Dynasty (1271-1368)

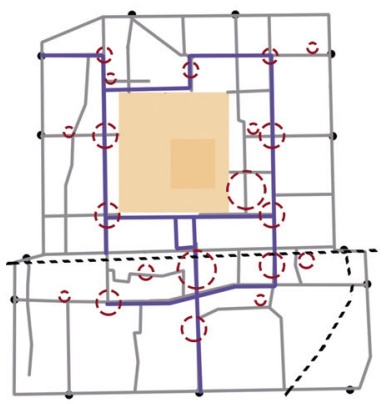

(d) Republic of China (1912-1949)

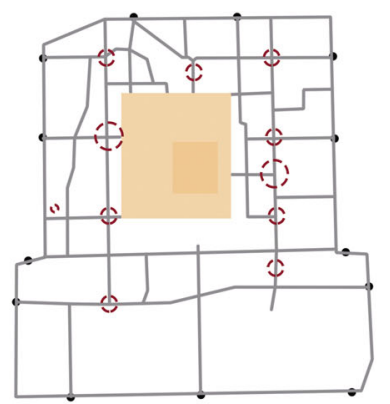

(b) Ming Dynasty (1368-1644)

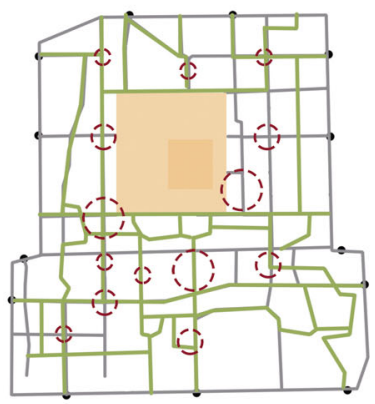

(e) Exploration Period of the People's Republic of China (1949-1977)

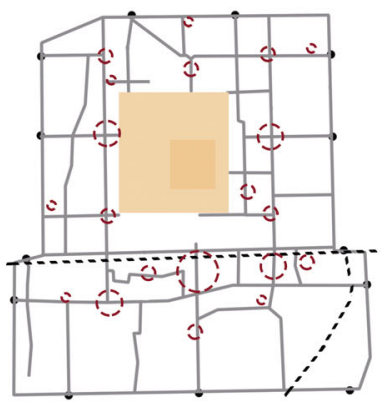

(c) Qing Dynasty (1644-1911)

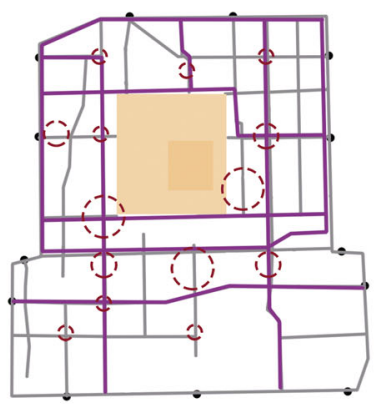

(f) Reform and Opening-up Period of the People's Republic of China (1978-)

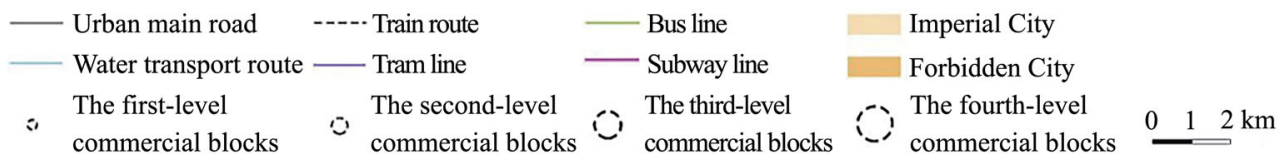

Figure 8 The overlay sketch maps of the major traffic modes and commercial blocks in different periods (Source: Figures were redrawn by the authors based on the originals from the following sources: a-c. Wang, 2011; d. Hou, 1988; e. Beijing Geological and Topographic Survey Department, 1976; f. Google Earth, 2013)

\section{Conclusions and discussion}

Using the space syntax method, from the perspective of layout form, topological structure, traffic mode, and change of street network, we examined the potential evolution rules of layout structure and hierarchy of the commercial blocks in ancient Beijing city.

In general, the rise and fall of city commercial blocks and migration was highly associated with the movement shown in space syntax. The important laws of the commercial blocks in the process of evolution were summed up as follows. (1) In different periods, the 
street network had a corresponding morphological and social structure. The process of evolution of the corresponding commercial blocks from "symmetrical axis-double-center structure-tripartite-confrontation situation" also revealed the related economic, political, and cultural characteristics. (2) The overall high accessibility could promote the commercial prosperity; the long-distance commuting efficiency could limit the development of commercial blocks during the Ming and Qing dynasties, while traffic became the major factor during and after the Republic of China. (3) The commercial block layout was consistent with the circular tendency of core streets. At the same time, the centripetal development of the street network could guide the agglomeration effect of commercial blocks, whereas centrifugal development could lead commercial blocks toward outward evacuation. (4) The layout of the commercial blocks was selected from the traffic node of the "location center", which depended on accessibility, and turns to the traffic commuting tendency of "flow center", which depended on traffic flow. (5) Originally relying on the accessibility of transportation node as location center, the layout of commercial blocks has come to depend on the crossing ability of the commuting flow center. The change of traffic mode mainly affected the adjustment of the first-class commercial blocks, which easily led to overall layout mutation. Meanwhile, the traffic levels had an obvious positive hierarchical relation with the secondor third-level commercial blocks. (6) Most of the commercial blocks occupied advantageous locations at transportation centers, but there were also a few dislocations. After the founding of the People's Republic of China, the mismatched condition became more prominent, showing that traffic development gradually shortened distances. Commercial blocks needed to seek other points of interest rather than traffic attraction to improve the commercial space.

The multiple characteristics of the commercial blocks throughout their diachronic evolution has been further considered.

(1) Urban centripetal-centrifugal siphon effect on the structure of commercial blocks

Since the second half of the 20th century, the layout of Beijing city has undergone a process from a single-center to multi-center structure. The centripetal and centrifugal degree of the city structure could be seen in the street networks of radioactive ray and circular structure, and showed a positive correlation between the aggregation and dispersion of the ancient city commercial blocks' layout. The single-center structure strengthened the accessibility of the central area with loop and radiation. Furthermore, the commercial blocks certainly had a siphon effect, resulting in a large number of city functions being concentrated in the central region, causing serious city congestion and working-housing imbalance. At the present stage of functional evacuation and structural adjustment, commercial blocks have gradually shifted from a balanced symmetrical distribution to a pattern with central circle agglomeration and peripherical multipolar decentralization. At the same time, the expansion of the peripheral commercial blocks has played an effective role in the evacuation of the ancient city commercial function, gradually balancing the space dislocation between living and employment. However, it would take a long time to complete the balance from siphon effect to functional radiation.

(2) Evolution of commercial blocks from mutation node to smooth development

In the long history of the evolution of the ancient city commercial block, the commercial structure and hierarchical system mutated during the Ming and Qing dynasties and the Republic of China, while gentle development occurred in the exploration period and Reform 
and Opening-up Period of the People's Republic of China. There were many reasons for this pattern change, among which the transformation in transportation mode led to the change of layout of the first-level commercial blocks in the Ming and Qing dynasties and the Republic of China, and the change of urban form from closed to open with the breaking of the symmetrical pattern. Besides traffic, city policy changes also led to node mutations, such as the commerce prohibition policy in the inner city during the Qing Dynasty. The prosperity of city commerce disappeared at one time. When this city policy was relaxed, however, city commerce redeveloped in the original location. However, after the founding of the People's Republic of China, no mutations happened in commercial level and layout. Thus, the layout of commercial blocks followed a certain spatial logic and historical path. Economic activities always occupied the core streets of the city center with the advantages of location. The layout of the commercial blocks was always in favor of developments in commodity transportation and crowd-flow gathering in the city. When occupying an advantageous location and forming an activity center, the basic stability of the spatial logic and layout structure in the process was easily reached. Major events, such as the implementation of the reform and opening-up policy, and the hosting of the 2008 Olympic Games, did not cause mutation to the commercial blocks of the ancient city.

(3) Adaptation of traditional commercial blocks to the needs of the modern city

The ancient city is a crucial part of Beijing as a historical and cultural city. The chessboard streets and alley texture are the key points for protection. Affected by the difference in time at which they sprang up and the original commercial foundation, the three major commercial blocks of Xidan, Wangfujing, and Qianmen, have formed various developmental models that meet the needs of modernization. With the expansion of commercial scale, and a concentration of modern shopping malls, the Xidan Block has developed as a typical high-end commercial block, and its cultural succession developed rapidly without continuity. As a traditional high-level commercial block, the Qianmen Block has changed little in size, but greatly in its attributes. It made full use of all kinds of time-honored commercial streets and hu tong (alley) texture, with the interaction of historical, cultural and commercial activities gradually transferring to the tourism business. Consumer groups have gradually focused on tourists. As for the development of Wangfujing Block, it had both historical and cultural elements as well as modern shopping malls, providing services to citizens and tourists alike. The three different development patterns came from a different consumer orientation, as well as their own resources and spatial logic.

By analyzing the evolution of the commercial center in ancient Beijing city, the results not only showed the potential law between the development of commercial centers and changes in street networks, but could also be used in future planning to predict the location of new commercial centers. How to reach a balance between cultural continuation and functional adaptation in old cities is a problem that nearly all countries continuously face. This research provided a planning reference for such old cities with similar realities in terms of the development of commercial centers and street networks.

\section{References}

Beijing Geological and Topographic Survey Department, 1976. Beijing Atlas. Internal Material. (in Chinese)

Cervero R, Kang C D, 2011. Bus rapid transit impacts on land uses and land values in Seoul, Korea. Transport 
Policy, 18(1): 102-116

Chen K Q, 1984. Langqian Notes (Mandarin: lang qian ji wen chu bi). Beijing: Chunghua Book Company. (in Chinese)

Chen Z F, 1991. Research of Beijing (Mandarin: yan du cong kao). Beijing: Beijing Ancient Books Publishing House. (in Chinese)

Chiaradia A, Hillier B, Schwander C et al., 2012. Compositional and urban form effects on centers in Greater London. Urban Design and Planning, 165(DP1): 21-42.

Fan H, 2008. City, Market and Shipping. Beijing: Academy Press. (in Chinese)

Gao S F, 1989. Research on the evolution and location of Beijing markets in history. Acta Geographica Sinica, 44(2): 129-139. (in Chinese)

Giannopoulou M, Roukounis Y, Stefanis V, 2012. Traffic network and the urban environment: An adapted space syntax approach. Procedia - Social and Behavioral Sciences, 48: 1887-1896.

Hillier B, 1996. Space is the Machine: A Configurational Theory of Architecture. Cambridge: Cambridge University Press.

Hillier B, Yang T, Turner A, 2012. Normalising least angle choice in Depthmap and how it opens up new perspectives on the global and local analysis of city space. Journal of Space Syntax, 3(2): 155-193.

Hong L, Chen X, Mo Z et al., 2015. Rail transit impact on the development of commercial space in Zhuhai. International Conference on Transportation Engineering, 1832-1838.

Hossain N, 2014. History of commercial development in Dhaka and the spatial significance of spontaneous retail growth. IOSR Journal of Humanities and Social Science, 19(11): 66-73.

Hou R Z, 1980, Beijing History. Shanghai: Shanghai People's Publishing House. (in Chinese)

Hou R Z, 1988. Beijing Historical Atlas. Beijing: Beijing Publishing House. (in Chinese)

Hou R Z, 2009. The Life Mark of Beijing City. Beijing: SDX Joint Publishing Company. (in Chinese)

Hou R Z, Tang X F, 2000. Beijing Historical Geography. Beijing: Beijing Yanshan Press. (in Chinese)

Li X, Lv Z H, Zheng Z G et al., 2015. Assessment of lively street network based on geographic information system and space syntax. Multimedia Tools and Applications, 76 (17): 17801-17819

Nahid M, Agust G, 2014. Street networks in relation to landforms: Implications for fast-growing cities. Journal of Geographical Sciences, 24(2): 363-381.

Nayeem B, Sharmin F, Hossain S M S, 2015. Exploring possible extension to commercial development of Comilla City, Bangladesh: A perspective from space syntax. Asian Journal of Applied Science and Engineering, (4): 68-77.

Porta S, Latora V, Wang F H et al., 2012. Street centrality and the location of economic activities in Barcelona. Urban Studies, 49(7): 1471-1488.

Qi D Z, 2011. Beijing Commercial History. Beijing: People's Publishing House. (in Chinese)

Qi D Z, Ren A T, 2014. Changes of Modern Business in Beijing. Beijing: Capital University of Economics \& Business Press. (in Chinese)

Scoppa M D, Peponis J, 2015. Distributed attraction: The effects of street network connectivity upon the distribution of retail frontage in the city of Buenos Aires. Environment and Planning B: Planning and Design, 27(2): 280-280.

Sevtsuk A, 2010. Path and Place: A Study of Urban Geometry and Retail Activity in Cambridge and Somerville, MA. Cambridge: Massachusetts Institute of Technology.

Shen T Y, Zhou L, Wang L W et al., 2015. Traffic network point of services location choice: A case study of the central city area of Beijing. Progress in Geography, 34(8): 947-956. (in Chinese)

Sheng Q, 2011. Changing centralities under urban configurational 'scale-structure': Pondering the spatial conditions for market and retail areas in Beijing. Netherlands: Delft University of Technology.

Sheng Q, 2012. Distribution logic of local public space: A spatial configuration analysis on the local shops inside 222 urban blocks in the Third Ring of Beijing. International Urban Planning, 27(6): 61-68. (in Chinese)

Sheng Q, Han L F, 2013. Distribution of shops and markets in old Beijing based on scale-structure in movement 
networks. Journal of Tianjin University (Social Sciences), 15(2): 122-130. (in Chinese)

Tsou K W, Cheng H T, 2013. The effect of multiple urban network structures on retail patterns: A case study in Taipei, Taiwan. Cities, 32(4): 13-23.

Turner A, 2007. From axial to street-center lines: A new representation for space syntax and a new model of route choice for transport network analysis. Environment \& Planning B: Planning \& Design, 34(3): 539-555.

Wang C J, Ducruet C, Wang W, 2015. Evolution, accessibility and dynamics of street networks in China from 1600 BC to 1900 AD. Journal of Geographical Sciences, 25(4): 451-484.

Wang F H, Antipova A, Porta S, 2011. Street centrality and land use intensity in Baton Rouge, Louisiana. Journal of Transport Geography, 19(2): 285-293.

Wang F H, Chen C, Xiu C L et al., 2014. Location analysis of retail stores in Changchun, China: A street centrality. Cities, 41: 54-63.

Wang Y, 2011. Hutong and Beijing. Beijing: China Cartographic Publishing House. (in Chinese)

Wang Y Q, Chen Z N, Tan S J, 2015. Research on the structural relationship of metro accessibility, passenger flows and retail business in metro sites: A case study of Guangzhou. Human Geography, 2015, 30(4): 66-71. (in Chinese)

Wu C Y, 1981. Records of Cities and Walls (Mandarin: chen yuan shi lue) (Volumes 1 and 9). Beijing: Beijing Ancient Books Publishing House. (in Chinese)

Wu L, Liu X D, Ye X Y et al., 2015. Permeability, space syntax, and the patterning of residential burglaries in urban China. Applied Geography, 60: 261-265.

Wu L P, Zhang Y C, Zhou S Y, 2016. Production and Reproduction of Urban Commercial Cultural Space: A Study on the Spatial Succession of Urban Commercial Culture in Beijing in Recent 10 Years. Nanjing: Southeast University Press. (in Chinese)

Wu Z Q, Dai X Z, 2001. The study on the spatial structure of Beijing's commercial centers. City Planning Review, 25(10): 15-19. (in Chinese)

Yang W Y, 1994. The retailing and services center and network of Beijing: Then, now and long before. Acta Geographica Sinica, 49(1): 9-17. (in Chinese)

Yu M Z, 1983. The Old Tales Research (Mandarin: ri xia jiu wen kao). Beijing: Beijing Ancient Books Publishing House. (in Chinese)

Zhang X H, 2009. Ancient Capitals and Cities. Nanjing: Jiangsu People's Publishing House. (in Chinese)

Zhang Z, Xia H, Sun J, 2014. Catalytic effect of underground commercial space of city and its design method: Take underground mall of Hangzhou Wulin square as an example. In: Xia H S, Zhang Y N (ed.). The 2nd International Symposium on Rail Transit Comprehensive Development (ISRTCD) Proceedings. Berlin, Heidelberg: Springer.

Zhou S Y, 1999. Beijing's commercial orientation and the boundary between urban and rural areas during the Yuan, Ming and Qing dynasties. Journal of Beijing Normal University (Social Science), (1): 83-92. (in Chinese)

Zhu Y X, 1982. Records of Alleys in Beijing (Mandarin: jing shi fang xiang zhi gao) (Volume II). Beijing: Beijing Ancient Books Publishing House. (in Chinese) 